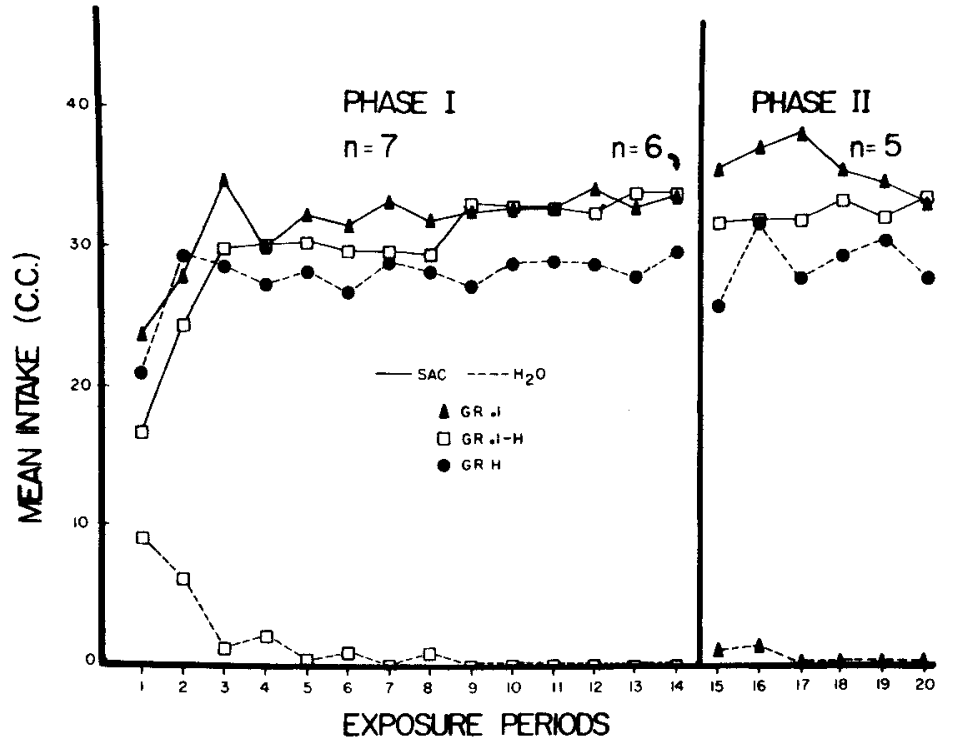

Fig. 2. Mean intake of Groups .1-H, .1, and $\mathrm{H}$ as a function of exposure periods.

interaction $(F=11.24, \quad \mathrm{df}=13 / 160$, $p<.01)$. SAC intake increased significantly with periods $(F=3.25$, $\mathrm{df}=13 / 77$, $p<.01)$. The Groups by Periods interaction was not significant. Examination of Group 1 in Period 15 reveals that exposure to a single tube of .1\% SAC had essentially the same effect on subsequent choice behavior as exposure to a single tube of $1 \% \mathrm{SAC}$, namely, to elevate relative $S A C$ intake.

Two interconcentration comparisons are noteworthy. First, relative water intake of the choice groups increased with SAC concentration. Second, a higher-SAC-thanwater intake emerged in clear fashion sooner in Group .1-H than in Group 1-H.

\section{DISCUSSION}

In food deprived rats, the reward value of a "sweet taste" is greater than in nondeprived rats (Sheffield \& Roby, 1950). To the rat which has been deprived of water (and which has deprived itself of food) SAC is a potential source of two types of reinforcing stimulation: fluidity and sweetness. That more SAC than water is ultimately consumed by water-deprived rats indicates that this potential may, under appropriate conditions, be realized. It is not clear, however, why the initial response of thirsty rats is to consume more water than SAC. One possibility is that SAC acquires an aversive taste property (e.g., bitterness) under water deprivation conditions. This view is supported by the finding of Strouthes \& Navarick (1967) that higher water than SAC intakes occurred in thirsty rats within the first $10 \mathrm{~min}$ of exposure. The immediacy of the effect suggests involvement of a gustatory mechanism. Also, the finding that less $1 \% \mathrm{SAC}$ is initially consumed from a single tube than water from a single tube (Fig. 1) would seem to indicate an aversive response.

The present hypothesis states that the aversiveness of SAC increases with concentration, but the sweetness of the substance remains sufficient to induce drinking at least up to a $1 \%$ concentration. The initial "preference" for water may be attributed to a difference in "palatability" between SAC and water, and possibly, to prior learning of an approach response to water.

Continued fluid intake conceivably initiates two processes. First, it may cause progressive reductions in thirst over days

\author{
J. J. PERSENSKY, R. J. SENTER, and R. B. \\ JONES, 2 University of Cincinnati, Cincin- \\ nati, Ohio 45221
}

The present study was an attempt to investigate the "stress reduction" theory of alcoholism thrnugh an attempt to link experimentally induced neurosis in rats with subsequent preference for alcohol. The results are in contradiction to the "stress reduction"theory.

Noting that attempts to establish compulsive alcohol consumption in laboratory rats had generally failed, Clay (1964) instituted a series of exhaustive experiments in which and thereby diminish to some extent the aversiveness of SAC. Second, continued SAC consumption may produce some form of adaptation or adjustment to the aversiveness of SAC. On this hypothesis, relative water intake would be expected to increase with concentration due to increasing intensity of the aversive component. Modification of the initial SAC-water intake relationship would be expected to occur earlier, and water intake to drop more rapidly with lower concentrations due, first, to greater effectiveness of thirst reduction, and second, to more rapid adaptation.

\section{REFERENCES}

BOLLES, R. C. The interaction of hunger and thirst in the rat. Journal of Comparative \& Physiological Psychology, 1961, 54, 580-584. COLLIER, G., \& BOLLES, R. C. Hunger, thirst and their interaction as determinan ts of sucrose consumption. Journal of Comparative \& Physiological Psychology, 1968, 66, 633-641.

SHEFFIELD, F. D., \& ROBY, T. B. Reward value of a non-nutritive sweet taste. Joumal of Comparative \& Phy siological Psy chology, 1950, 43, 471-481.

STROUTHES, A., \& NAVARICK, D. J. Sacchatine and $\mathrm{H}_{2} \mathrm{O}$ consumption as a function of $\mathrm{H}_{2} \mathrm{O}$ deprivation. Psychonomic Science, 1967, 9, 523-524.

\section{NOTES}

1. This study constituted part of an Honors project carried out by the senior author under the supervision of the junior author. A paper based on this investigation was read at the 1968 meeting of the Eastern Psychological Association, Washington, D. C.

2. Procedural difficulties forced a reduction in $N$ from seven to six in Period 14. In the following trend analyses, the indicated number of dfs was subtracted from the within-Ss error term: Group .1-H, 2; Group 1-H, 2; Group.1 vs Group H, 2; Group 1 vs Group H, 2; Groups .1, 1 , and $H, 1$ each.

\title{
Alcohol consumption in rats after experimentally induced neurosis
}

rats were exposed to many different situations thought to be etiologically related to alcoholism. Because of the commonly held hypothesis that alcohol consumption can reduce the detrimental effects of stress, Clay included among her experimental situations the insoluble discrimination problem (Maier, 1949) which apparently produces conflict sufficiently severe to result in the aberrant behavior known as "experimental neurosis" in rats. If the stress produced by such a circumstance is sufficient to cause severely maladaptive behavior, it would seem that animals would seek the reduction of the stress through any means available to them. Hence, if alcohol 
could provide a source of stress reduction, animals subjected to the insoluble problem should drink the EtOH if it is available to them. Although Clay's results were significant in that the stressed animals consumed more alcohol than the unstressed animals, she states that her experimental design involved a confounding factor, i.e., the stressed animals were given less food than were the unstressed animals, thus Clay did not control for additional calorie need in the stressed animals.

Since the Maier-type insoluble problem is one of the few "stressful" conditions sufficiently severe to produce, with reasonable reliability, truly maladaptive behavior in the rat, it would seem that if exposure to any stressful condition could induce significant alcohol consumption in rats, this one should do it.

The present study is essentially a repetition of Clay's procedure with the possible confounding due to food deprivation eliminated. This procedure would intuitively provide near ideal conditions under which stress avoidance as a factor in inducing alcohol consumption can be examined.

\section{METHOD}

The apparatus was a modified Lashley jumping stand with an adjustable electrified grid serving as the jumping platform. The grid measured $6 \times 18$ in. and could be adjusted from 0 to 16 in. from the stimulus doors. Each of the two doors $(8 \times 8$ in.) could be opened either mechanically by $E$ or automatically by $S$ passing through a light beam activating a photoelectric cell. The voltage applied to the grid could be adjusted between 0 and $75 \mathrm{~V}$. The stimuli were black and white cards $(8 \times 8$ in.) which could be attached to either of the two doors.

Twenty-six 90- to 120-day-old rats were exposed to a modified Lashley jumping procedure in which the animals were first required to learn a black-white (randomly alternated) discrimination to a criterion of 40 successive correct discriminations from 16 in. to avoid shock over a period of 2 days, 20 of 20 correct on each day. Of the original 26 animals only 20 reached criterion. The animals reaching criterion were randomly assigned to the two experimental conditions. Eleven of the animals (F) were presented an insoluble problem (two white or two black doors) and tested until they exhibited apparent fixation. Apparent fixation was defined as 15 consecutive responses to the same side followed by five consecutive trials involving opening the other door and placing the animal in front of that door. In all but two cases the $F$ animals continued to jump to the side to which they had become fixated. Only the animals which exhibited fixation were included in the subsequent manipulations. The second

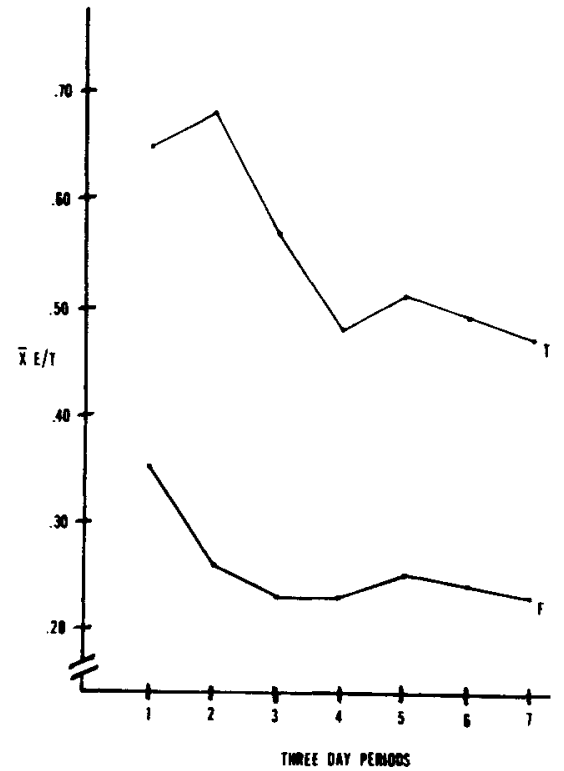

Fig. 1. Mean relative alcohol consumption (E/T) for the 21 -day post ad lib period (3-day intervals) for Groups $T$ and $F$.

group (T) were not exposed to the fixation paradigm but were continued on the discrimination training procedure for the same number of trials as the mean necessary to produce fixation $(\bar{X}=23)$ for the $F$ group. During the training and fixation the animals were housed individually with ad lib food and water. Following fixation, or further training, the animals were housed in their individual home cages with ad lib food, water, and $7 \%(\mathrm{~V} / \mathrm{V})$ e thanol for 21 days.

\section{RESULTS}

The data analyzed were derived from the relative alcohol consumption expressed as the ratio of $7 \%(\mathrm{~V} / \mathrm{V})$ EtOH solution ingested to the total liquid consumed, $\mathrm{E} / \mathrm{T}$, for each 24-h period for 21 days. A t test for independent samples resulted in a $\mathbf{t}=2.80$ $(\mathrm{df}=16, \mathrm{p}<.05)$ with the $\mathrm{T}$ group mean $\mathrm{E} / \mathrm{T}=.54$ and the $\mathrm{F}$ group mean $\mathrm{E} / \mathrm{T}=.26$.

Examination of Fig. 1 indicates that the relationship of the groups' drinking held constant over the 21-day posttraining period, with the $\mathrm{F}$ group showing consistently lower EtOH preference during this time.

\section{DISCUSSION}

The results of the data analysis indicated that the F group (stressed) actually showed a significantly lower preference for EtOH solution than did the T group (not stressed). Clay presents data which indicate that there was a significant difference between stressed and nonstressed animals but in the opposite direction, i.e., the stressed animals actually exhibited a greater preference for alcohol, as measured by absolute intake. The findings of the present study indicate that there is a statistically significant difference between relative alcohol consumption for the stressed and nonstressed animals, but that the stressed animals actually drank less EtOH than did the nonstressed animals. This finding is an apparent contradiction of Clay's results and of the "stress" theory of alcoholism.

Recently, some investigators (Senter, Smith, \& Lewin, 1967; Senter \& Persensky, 1968; Persensky, Senter, \& Jones, 1968) have repeatedly reported failure to induce persistent voluntary EtOH consumption in rats through the use of "stressful" conditions. The present study tends to confirm these writers' growing conviction that stress, and/or stress avoidance through alcohol consumption, simply do not constitute conditions which are effective in producing "addictive" behavior in laboratory rats. This study provides an addition to the growing body of evidence (e.g., Senter, Smith, \& Lewin, 1967; Senter \& Persensky, 1968; Persensky, Senter, \& Jones, 1968 ; Clay, 1964; Korman \& Stephens, 1960) showing that exposure of laboratory rats to conditions which follow logically from a "stress reduction" theory of alcoholism fails to produce results even vaguely analogous to "addictive" behavior. Although the above mentioned authors working under the "stress" theory have established factors which do increase alcohol preference, such increases have been relatively small and unreliable. No procedure has produced behavior indicating a persistent need for alcohol.

There are, of course, many possible reasons for the consistent failure to support such a theoretical framework in the laboratory. Among these various reasons there exists the concrete possibility that the widely held "stress reduction" theory of alcoholism does not describe conditions which can adequately account for the etiology of the disorder.

\section{REFERENCES}

CLAY, M. Conditions affecting volun tary alcohol consumption in rats. Quarterly Journal of Studies on Alcohol, 1964, 25, 36-55.

KORMAN, M., \& STEPHENS, H. Effects of training on the alcohol consummatory response in rats. Psychological Reports, 1960, 6, 327-331.

MAIER, N. R. F. Frustration. New York: MoGraw-Hill Book Co., Inc., 1949.

PERSENSKY, J. J., SENTER, R. J., \& JONES, R. B. Induced alcohol consumption through positive reinforcement. Psychonomic Science, $1968,11,109-110$.

SENTER, R. J., SMITH, F. W., \& LEWIN, S. Ethanol ingestion as an operant response. Psychonomic Science, 1967, 8, 291-292.

SENTER, R. J., \& PERSENSKY, J. J. Effects of environment on ethanol consumption after conditioning. Quarterly Joumal of Studies on Alcohol, 1968, 29, 856-862. NOTES

1. This study represents a portion of the effort undertaken under USPHS Grant No. 11063-03.

2. Now with the United States Air Force. 